\title{
DEVELOPMENT OF EFFERVESCENT GRANULE OF CORN MILK, SUPPLEMENTED WITH PROBIOTICS LACTOBACILLUS STRAIN SHIROTA
}

\author{
RENI HIOLA a , ROBERT TUNGADI ${ }^{*}$ \\ aDepartment of Public Health, Faculty of Sport and Health, State University of Gorontalo, Gorontalo, Indonesia. \\ bDepartment of Pharmacy, Faculty of Sport and Health, State University of Gorontalo, Gorontalo, Indonesia \\ Email: rtungadi@yahoo.com
}

Received: 21 May 2018, Revised and Accepted: 29 Jun 2018

\section{ABSTRACT}

Objective: One of the materials which can be formulated into probiotics drink is corn milk. It has nutrient contents such as vitamin A, B, C, minerals, and fibres. The objective of this study was to develop and evaluate the probiotic drink of corn milk which was formulated into an effervescent granule.

Methods: The first step was carried out to make corn extract with the addition of Lactobacillus strain Shirota and incubated 24 h at $40{ }^{\circ} \mathrm{C}$ to gain corn milk. After that, corn milk was centrifuged to get filtrate and dried by oven $40{ }^{\circ} \mathrm{C}$ for $2 \mathrm{~d}$ to gain dry powder. Then corn milk powder was formulated into effervescent granule ( 3 formulas) using different ratio of acids. The method which used in making effervescent granule of corn milk was wet granulation. All formulas were done evaluations including physical and chemical properties of granule and hedonic test.

Results: The results showed that formula 1 (only citric acid $23.84 \%$ ) gave unsatisfactory results particularly on the evaluation tests such as LOD 9.64\%, dissolution time 3.25 min, moisture content $10.67 \%$ and hedonic test which did not meet the requirements. Otherwise, formula 2 (only tartaric acid 23.84\%) and formula 3 (citric acid 7.94\% and tartaric acid 15.9\% combination) showed satisfactory results for all evaluation tests of granules. Particularly formula 3 gave $\mathrm{pH} 5$ on $\mathrm{pH}$ test which was the same as pH lactic acid for fermentation and LOD $4.34 \%$, MC $4.53 \%$, $\mathrm{\rho b} 0.53$ $\mathrm{g} / \mathrm{ml}, \rho \mathrm{t} 0.62 \mathrm{~g} / \mathrm{ml}$ and hedonic test around $80 \%$.

Conclusion: Formula 3 was the best formulation based on the evaluation and the stability of corn milk effervescent granule.

Keywords: Corn milk, Effervescent granule, Lactobacillus strain Shirota, Probiotics

(C) 2018 The Authors. Published by Innovare Academic Sciences Pvt Ltd. This is an open access article under the CC BY license (http://creativecommons.org/licenses/by/4.0/) DOI: http://dx.doi.org/10.22159/ijap.2018v10i5.27459

\section{INTRODUCTION}

Corn commodity (Zea mays L.) is still highly demanded by the world community. World corn demand reaches 770 million tons/year, $42 \%$ of which is a requirement of people in the American continent. In Indonesia, corn is an important foodstuff because it is the second source of carbohydrate after rice. In some areas of Indonesia, corn is used as the main food ingredient, and also as animal feed ingredient and industry, the productivity of maize at the national level reaches 3.4 tons/ha. Research by various government and private agencies has resulted in corn cultivation technology with a productivity of 4.5-10.0 tons/ha, depending on the potential land and production technology applied [1]

Sweet corn is a short-lived plant, easy to grow and nourish, fast harvest, good to eat but not lasting [2]. Aside from being one of the main food sources, corn is also an important source of raw material for the industrial sector and can be used for industrial basic materials, beverages, syrup, paper, oil, vegetable, milk such as corn milk especially important for health, especially for someone who is allergic to cow's milk. Consumption of milk in Indonesia is still low, whereas milk has many benefits. One of the reasons people do not consume milk is due to lactose intolerance (not resistant to milk sugar or lactose), where the stomach cannot digest milk sugar.

Corn milk is a probiotic drink produced from the fermentation of Lactobacillus strain Shirota which contains carbohydrates, proteins, fiber, vitamins and minerals such as calcium, phosphorus, iron, vitamins A, B, and C. Therefore, corn milk is also called probiotic drinks for health that has the utility to diet, prevent cancer and diabetes, decrease cholesterol, and constipation $[3,5]$. Based on this, the corn milk can be formulated into an effervescent granule dosage form.

Effervescent mixtures have been reasonably well known throughout the years since alongside the restorative estimation of the specific arrangement, they offered general society a novel measurements shape that was fascinating to get ready. Moreover, they gave a charming taste because of the carbonation which covered the frightful taste of the medications $[4,6]$. The selection of elements for effervescent granules relies upon both upon the necessity of the assembling procedure. The required fixings are no less than one acid and no less than one base. The construct must discharge carbon dioxide in light of response with the acids. These are typically arranged from a blend of citrus and tartaric acid instead of from a solitary acid due to the utilization of either acid alone causes troubles. Effervescent salts incorporate the accompanying fixings, which really create the foam: sodium bicarbonate, citrus acid, and tartaric acid. At the point when added to water the acids and base respond to free carbon dioxide, bringing about bubbling [4].

Based on this reason, developing a new corn-based product in the form of effervescent granule is an avenue to raise the awareness on corn consumption. Besides that, the sweet taste of corn milk along with its aroma and balanced nutritional content compared to other types of vegetable-based beverage are seen as the upper hand of this product [2].

Furthermore, the development of this product will be based on sensory acceptance so that it is expected that the product will be preferred in the market. There are several studies that emphasized a focus on cow milk. However, the number is very inadequate when it comes to the studies on corn milk effervescent granule especially the physicochemical and sensory properties of corn milk effervescent granule with culture. This research aimed to develop corn milk into effervescent granule product with corn extract as a probiotic drink using the culture of Lactobacillus strain Shirota.

\section{MATERIALS AND METHODS}

\section{Materials}

Lactabacillus strain Shirota, provided by Yakult Indonesia co., was used in these experiments. Corn and sucrose was bought from traditional market. Tartaric acid, citric acid, and sodium bicarbonate were bought from Brataco Chem co. Dextrin and saccharin (Sigma Aldrich). 


\section{Methods}

\section{Preparation of sweet corn milk}

The sweet corn variety used in this study was Pertiwi-2 that was harvested on the 21rd day after silking of the corn plant. The sweet corn was acquired from the conventional market in Gorontalo. To set up the corn drain, the sweet corn cobs were initially husked, the silks removed and washed with water. The seeds were then separated from the cleaned cobs using knives. The corn seeds $12.5 \%$ $\mathrm{w} / \mathrm{v}$ was extracted using a fruit extractor (Lion star) to produce a milk solution. The corn milk solution was then filtered through a filter and added sucrose $12.5 \% \mathrm{w} / \mathrm{w}$. After that, the corn milk solution was pasteurized at $70{ }^{\circ} \mathrm{C}$ and allowed to cool then added Lactobacillus strain Shirota $10 \% \mathrm{v} / \mathrm{v}$ after that it was incubated at 40 ${ }^{\circ} \mathrm{C}$ for $24 \mathrm{~h}$ resulting corn milk.

\section{Preparation of corn milk into powder form}

The fermented corn milk was centrifuged for $15 \mathrm{~min}$ at $3000 \mathrm{rpm}$ and taken the corn milk filtrate after that it was dried in the oven at $40{ }^{\circ} \mathrm{C}$ for $2 \mathrm{~d}$ then obtained in the form of a coarse powder and smoothed with homogenizer to obtain a homogeneous fine powder.

\section{Formulation of corn milk effervescent granules}

Corn milk effervescent granules were prepared by wet granulation method.

Corn milk powder formulation was made into 3 formulas which was the same composition of corn milk powder but different acids use. Formula I contained only citric acid $23.84 \%$ and formula II only tartaric acid $23.84 \%$. Meanwhile, Formula III contained citric acid and tartaric acid combination (7.94\% and $15.9 \%)$. The compositions of each formula can be seen in table 1 .

All the ingredients are weighed then mixed with corn milk powders, citric acid, tartaric acid, sodium bicarbonate, saccharin, sucrose and dextrin. The binder (Na CMC) and lemon flavor were added and formed into a paste and granulated using sieve No. 40 . This mass was passed through sieve No. 20 to get granules and these granules were dried in hot air oven at $40^{\circ} \mathrm{C}$ and then they were packed in air tight container [2, 4-5]. This protocol was done for formula III. The same procedure was done for formula I (only citric acid) and II (only tartaric acid).

\section{Evaluation of corn milk effervescent granules}

\section{A. Physicochemical test}

\section{The water content test}

The wet granules are weighed then dried in the oven to obtain a fixed weight. The water content is calculated by the formula: [7-9]

Loss on Drying (LOD):

$$
\% \text { LOD }=\frac{\text { Wet granular weight }- \text { Dry granular weight }}{\text { Wet granular weight }} \times 100 \%
$$

\section{Moisture content (MC):}

$$
\% \text { LOD }=\frac{\text { Wet granular weight }- \text { Dry granular weight }}{\text { Dry granular weight }} \times 100 \%
$$

\section{Angle of repose}

The fixed funnel method was employed to measure the angle of repose. A funnel was secured with its tip at a given height (h), above a graph paper that is placed on a flat horizontal surface. The blend carefully pored through the funnel until the apex of the conical pile just touches the tip of the funnel. The radius of the base of the conical pile was measured. The angle of repose $(\theta)$ was calculated using the following formula: $\operatorname{Tan} \theta=h / r$

Where, $\theta=$ Angle of repose, $h=$ Height of the cone, $r=$ Radius of the cone base. Values for the angle of repose $\leq 30^{\circ}$ usually indicate a free-flowing material and angles $240^{\circ}$ suggest a poorly flowing material, 25-30 show excellent flow properties, 31-35 show good flow properties, 36-40 show fair flow properties and 41-45 showing passable flow properties.

\section{Bulk density}

$15 \mathrm{~g}$ powder blend introduced into a dry $100 \mathrm{ml}$ cylinder, without compacting. The powder was carefully leveled without compacting and the unsettled apparent volume, Vo, was read. The bulk density was calculated using the following formula. $\rho b=M /$ Vo Where, $\rho b=$ Apparent bulk density, $\mathrm{M}=$ Weight of sample, $\mathrm{V}=$ Apparent volume of powder.

\section{Tapped density}

After carrying out the procedure as given in the measurement of bulk density the cylinder containing the sample was tapped 500 times initially followed by an additional taps of 750 times until difference between succeeding measurement is less than $2 \%$ and then tapped volume, Vf was measured, to the nearest graduated unit. The tapped density was calculated, in gm per ml, using the following formula. $\rho$ tap $=M / V f$ Where,$\rho t a p=$ Tapped density, $M=$ Weight of sample, $\mathrm{Vf}=$ Tapped volume of powder.

\section{Hausner's ratio}

Hausner's ratio is an indirect index of ease of powder flow. It is calculated by the following formula. Hausner's Ratio=Tapped density $(\rho t) /$ Bulk density $(\rho b)$ Where, $\rho$ t tapped density and $\rho b$ is bulk density. Lower Hausner's ratio $(<1.25)$ indicates better flow properties than higher ones, between 1.25 to 1.5 showing moderate flow properties and more than 1.5 poor flow.

\section{Effervescent cessation time}

$100 \mathrm{ml}$ of distill water was taken in $250 \mathrm{ml}$ beaker, one dose of effervescent granules were poured in to the beaker, effervescent cessation time and effervescent production was observed. The effervescent granule soluble time ranges from 1-2 min. When the granules are well dispersed in water with a time of 2 min, the preparation meets the soluble time requirement $[10,11]$.

\section{pH test}

$\mathrm{pH}$ measurement was made by dissolving $5 \mathrm{~g}$ of corn milk effervescent granules into $150 \mathrm{ml}$ water then measured $\mathrm{pH}$ using $\mathrm{pH}$ meter.

\section{B. Hedonic test (the sensory evaluations)}

The sensory evaluation for formulations in step I and step II was conducted by following hedonic scale rating test using 30 untrained panelists. The panelists were asked to score the samples for preference of corn milk yoghurt characteristic on a scale of 1 to 6 , where scale 6 = really like, 5 = like, $4=$ rather like, $3=$ rather dislike, 2 $=$ dislike, and $1=$ really dislike. Thus, the scores were subjected to oneway analysis of variance and significant differences were evaluated by Duncan multiple range test using SPSS Statistic version 16.0 software. The best product was determined by giving weight to every characteristic based on prioritized score of the characteristic, i.e. 4 as the most prioritized characteristic; 3 as prioritized characteristic; 2 as less prioritized characteristic and 1 as the least prioritized characteristic. The priority of every characteristic can be seen at table 6 and 7. The results from every characteristic, based on hedonic evaluation, were presented in the order from the highest to the lowest on the average of hedonic scale. The total score of each formula was calculated by multiplying the weight with the score of ranking [3].

\section{RESULTS}

From the research that has been done, got the result of making effervescent granule of corn milk granules was as much as $205.29 \mathrm{~g}$ of effervescent granule which fulfill the standard of granule test. Making effervescent milk granules as the main nutritious substance is intended to obtain an interesting way for developing of natural materials in the form of effervescent preparations that are easy to use and practical, so it is expected to increase public interest in consuming natural materials such as corn milk effervescent granules as probiotic drink which supplemented Lactobacillus strain Shirota.

\section{Formulation of corn milk effervescent granules}

The formulation of corn milk effervescent granules was made into 3 formulas showing the same composition of each formula but different concentrations of acids use. All formulas can be seen in table 1 . 
Table 1: The composition of corn milk effervescent granules

\begin{tabular}{|c|c|c|c|}
\hline \multirow[t]{2}{*}{ The compositions } & \multicolumn{3}{|c|}{ The amount of materials (\%) } \\
\hline & F1 & F2 & F3 \\
\hline Corn milk powder & 20 & 20 & 20 \\
\hline Citric acid & 23.84 & - & 7.94 \\
\hline Tartaric acid & - & 23.84 & 15.9 \\
\hline Sodium bicarbonate & 27.04 & 27.04 & 27.04 \\
\hline Sucrose & 18 & 18 & 18 \\
\hline Saccharin & 0.1 & 0.1 & 0.1 \\
\hline Dextrin & 10 & 10 & 10 \\
\hline $\mathrm{Na} \mathrm{CMC}$ & 1 & 1 & 1 \\
\hline Lemon flavor & q. $s$ & q. $s$ & q. s \\
\hline
\end{tabular}

\section{Evaluation of corn milk effervescent granules}

A. Physicochemical test

The water content test

The results of water content observation of corn milk effervescent granules can be seen in following table 2 .

\section{Angle of repose}

The results of the angle of repose test can be seen in the following table 3.

\section{Bulk density}

The results of the bulk density of corn milk effervescent granules on each formula can be seen in table 4 .

\section{Tapped density}

The results of the tapped density of corn milk effervescent granules on each formula can be seen in table 5 .

\section{Effervescent cessation time}

The soluble time test is carried out by inserting 1 sachet $(5 \mathrm{~g})$ of effervescent powder into a glass cup filled with $100 \mathrm{ml}$ of water at a temperature of $25^{\circ} \mathrm{C}$.

Table 2: The results of water content

\begin{tabular}{llll}
\hline Formula & \% LOD & \% MC & the requirements of LOD and MC \\
\hline F1 & $9.64 \% \pm 0.25$ & $10.67 \% \pm 0.87$ & $\leq 5 \%$ \\
F2 & $4.53 \% \pm 0.36$ & $4.74 \% \pm 0.76$ & $\leq 5 \%$ \\
F3 & $4.34 \% \pm 0.56$ & $4.53 \% \pm 0.45$ & $\leq 5 \%$ \\
\hline
\end{tabular}

All values are reported as mean $\pm \mathrm{SD}(\mathrm{n}=3)$, This table showed that $\mathrm{F} 1$ containing only citric acid did not meet the requirements of LOD and MC. Otherwise, F2 (only tartaric acid) and F3 (citric acid and tartaric acid combination) had a percentage of LOD and MC below 5\%. It means that F2 and F3 meet the test requirements.

Table 3: The angle of repose of each formula of corn milk effervescent granules

\begin{tabular}{lllllll}
\hline Formula & $\mathbf{H}$ & $\mathbf{1} / \mathbf{2} \mathbf{D}_{\mathbf{1}}$ & $\mathbf{1} / \mathbf{2} \mathbf{D}_{\mathbf{2}}$ & Tan $\boldsymbol{\alpha}_{\mathbf{1}}$ & Tan $\boldsymbol{\alpha}_{\mathbf{2}}$ & the requirements of the angle of repose \\
\hline F1 & 1.5 & 8.5 & 9 & $19.39^{\circ} \pm 0.1$ & $18.41^{\circ} \pm 0.2$ & $\alpha \leq 40^{\circ}$ \\
F2 & 2 & 7.5 & 7.7 & $28.05^{\circ} \pm 0.3$ & $27.42^{\circ} \pm 0.5$ & $\alpha \leq 40^{\circ}$ \\
F3 & 2.5 & 8.2 & 8.5 & $30.45^{\circ} \pm 0.45$ & $31.34^{\circ} \pm 0.65$ & $\alpha \leq 40^{\circ}$ \\
\hline
\end{tabular}

All values are reported as mean $\pm \mathrm{SD}(\mathrm{n}=3)$, the table showed that all formulas gave good results of the angle of repose test and met the requirements.

Table 4: The tapped density test of corn milk effervescent granules

\begin{tabular}{llll}
\hline Formula & Granule weight $(\mathbf{g})$ & Granule volume $(\mathbf{m l})$ & Bulk density $(\boldsymbol{\rho b})(\mathrm{g} / \mathbf{m l})$ \\
\hline F1 & $19.86 \pm 0.68$ & $39 \pm 0.45$ & $0.50 \pm 0.55$ \\
F2 & $22.55 \pm 0.48$ & $45 \pm 0.34$ & $0.50 \pm 0.4$ \\
F3 & $21.59 \pm 0.27$ & $40 \pm 0.26$ & $0.53 \pm 0.26$ \\
\hline
\end{tabular}

All values are reported as mean $\pm \mathrm{SD}(\mathrm{n}=3)$

Table 5: The tapped density test of corn milk effervescent granules

\begin{tabular}{lllll}
\hline Formula & Tapped weight $(\mathrm{g})$ & Tapped volume $(\mathbf{m l})$ & Tapped density $(\boldsymbol{\rho}) \mathbf{( g / m l})$ & Hausner's ratio $(\boldsymbol{\rho} t / \rho b)$ \\
\hline F1 & $19.86 \pm 0.34$ & $35 \pm 0.22$ & $0.56 \pm 0.27$ & $1.12 \pm 0.41$ \\
F2 & $22.55 \pm 0.28$ & $40 \pm 0.18$ & $0.56 \pm 0.23$ & $1.12 \pm 0.34$ \\
F3 & $21.59 \pm 0.76$ & $35 \pm 0.36$ & $0.62 \pm 0.58$ & $1.16 \pm 0.35$ \\
\hline
\end{tabular}

All values are reported as mean $\pm \mathrm{SD}(\mathrm{n}=3)$ 


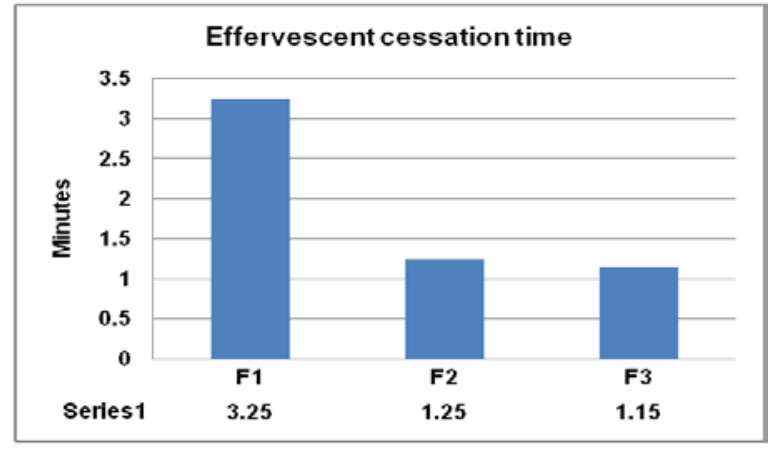

Fig. 1: Effervescent cessation time of each formula

The soluble time indicates the amount of time required by the powder in a serving size to be completely dissolved in a certain volume of water. According to Mohrle (1989), soluble time of good effervescent powder ranges is from 1-2 min [12]. In fig. 1 showed that the test results obtained by the time of dissolution of corn milk effervescent granules of formula 1 had a soluble time more $2 \mathrm{~min}$. So it can be that said it does not meet the requirements whereas formula 2 and 3 have soluble time less than $2 \mathrm{~min}$ so it can be said to meet the requirements.

\section{pH Test}

The results of $\mathrm{pH}$ test of corn milk effervescent granules showed F3 containing the combination of citric acid and tartaric acid gave $\mathrm{pH} 5$ which was the same as $\mathrm{pH}$ lactic acid for fermentation (fig. 2).

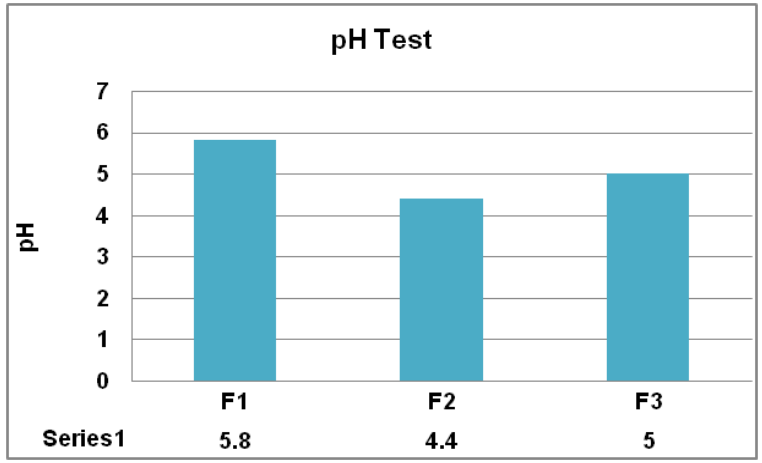

Fig. 2: pH test of corn milk effervescent granules

\section{Hedonic test (the sensory evaluations)}

\section{Texture of granules and color}

Texture is generally influenced by water content, fat content, protein levels and the structure of carbohydrates contained. The mixing of materials used in the manufacture of this effervescent powder makes a uniform powder shape. According Permana et al. (2012) stated that the addition of sweeteners can improve the texture of foodstuffs, for example with increased viscosity and the addition of weight of time. In table 6 , it was found that Formula 3 had a preferred percentage of $75 \%$ (highest compared to other formulas).

Table 6: The recapitulation result of the Hedonic test: texture and color

\begin{tabular}{|c|c|c|c|c|}
\hline \multirow[t]{2}{*}{ Formula } & \multicolumn{2}{|c|}{ Texture (\%) } & \multicolumn{2}{|c|}{ Color (\%) } \\
\hline & Like & Dislike & Like & Dislike \\
\hline F1 & 50 & 50 & 70 & 30 \\
\hline $\mathrm{F} 2$ & 45 & 55 & 60 & 40 \\
\hline F3 & 75 & 25 & 80 & 20 \\
\hline
\end{tabular}

Table 7: The recapitulation result of Hedonic test: flavor and taste

\begin{tabular}{lllll}
\hline Formula & Texture (\%) & \multicolumn{2}{c}{ Color (\%) } \\
\cline { 2 - 5 } & Like & Dislike & Like & Dislike \\
\hline F1 & 60 & 40 & 50 & 50 \\
F2 & 30 & 70 & 40 & 60 \\
F3 & 80 & 20 & 75 & 25 \\
\hline
\end{tabular}

Color assessment is used in organoleptic testing because color has an important role to the level of product acceptance visually. The panelist assessment of the effervescent powder color produced is approximately uniform. The resulting effervescent granule was yellowish. In table 6 of formula 3 had a preferred percentage of $80 \%$ (highest compared to other formulas).

\section{Aroma and taste of corn milk effervescent granules}

The smell of a product can be assessed by smelling the aroma produced from the product. The scent used was lemon flavor. In table 7 showed that Formula 3 was the best formula containing aroma $80 \%$ of favorite value, this result indicated that the panelist liked the scent.

The taste is a very important factor in determining the consumer's final decision to accept or reject a food product. In this study, the taste was assessed after the powder was dissolved in water, in this case being a beverage of effervescent granules. Table 7 showed that the panelist really like the taste i.e. F3 about $75 \%$ of preferred percentage with a soda-less flavor. Flavors such as soda are characteristic of effervescent powders dissolved in water because of the acid reacts with carbonates to form $\mathrm{CO}_{2}$ [13].

\section{DISCUSSION}

The first step of the corn milk making process was intended to make a probiotic drink by pasteurization using the heating process at 70 ${ }^{\circ} \mathrm{C}$ after that fermented by lactobacillus strain Shirota at $40{ }^{\circ} \mathrm{C}$. The purpose of pasteurization process was to eliminate spoilage and pathogenic microorganisms [14].

In general, corn contains a high amount of starch. The average content of starch in corn is estimated at around $10-11 \%$, yet the content of starch in sweet corn is lower than other varieties of corn. The starch content in corn is expected to play a role as a natural stabilizer in the product. Ultimately, the length of warming period likewise observably affected consistency; longer warming period expanded water retention by the cornstarch, with the goal that thickness additionally expanded. This marvel was likewise influenced by the extent of water which was included beforehand. The nearness of water and starch in a warmed condition will trigger gelatinization, and the gelatinized starch will build the thickness of the arrangement [3].

Sweet corn was chosen as a crude material because of its high sugar content contrasted with different assortments of corn. The real sugar contained in sweet corn is sucrose and typical sweet corn contains $9-16 \%$ sugar all in all [15]. Besides, sweet corn has been well known for its fragrance and sweet taste [2]. The particular taste of corn drain yogurt lies on its legitimate corn smell. Therefore, the expansion of yakult containing Lactobacillus strain Shirota can keep up the run of the mill yogurt season from yakult.

The second step, the development of fermented corn milk was made into effervescent granules and done some granule evaluations to determine the best formula based on different concentrations of 
adding acids. In the manufacture of effervescent preparations were used a combination of two kinds of acids, namely citric acid and tartaric acid than just one type of acid alone because the use of single acid alone will cause difficulties in the formation of foam. Citric acid used as a single ingredient will produce a mixture that is sticky and pollinated to powder. While the use of tartaric acid alone, the resulting powder will easily lose its strength and will clot. Sodium bicarbonate is used as the base reaction former and acts in neutralizing the citric acid and tartaric acid and can produce foam and liberate carbon dioxide as well as soluble in water [4].

Generally, the $\mathrm{pH}$ value of fermented corn milk is the ranges between 4.0 and $5.0[16]$. This product $\mathrm{pH}$ value is measured at $4.2 \pm 0.02$, so that the $\mathrm{pH}$ value of this product can be considered appropriate. During 4-week storage, the $\mathrm{pH}$ value $\mathrm{pH}$ value declined which was also found by Kim et al. (2009). The organic acid composition during storage condition undergoes continuous change, thus it affects the $\mathrm{pH}$ [17]. The decreasing $\mathrm{pH}$ value might be caused by lactic acid bacteria that have fermented most of the sugar sources (sucrose, glucose, and lactose) into lactic acid or another form of organic acids. The total titrated acid is represented by lactic acid as a result of the yakult fermentation, so the decreasing $\mathrm{pH}$ value can increase by storage in the fridge for $2 \mathrm{w}$.

The aged corn drain based yakult can be named probiotic drink since it had the total lactic acid microbes of $0.8 \times 107 \mathrm{CFU} / \mathrm{ml}$. As indicated by Tammime and Robinson (1989), the probiotic drink is required to contain $\geq 106 \mathrm{CFU} / \mathrm{ml}$ of total lactic acid bacteria. During the first $2 \mathrm{w}$ of storage, the total of lactic acid bacteria expanded [18]. Be that as it may, the quantity of the total of lactic acid microorganisms diminished from the third week to the fourth and the seventh day stretch of storage. The development takes after the microbial development bend where the development during the slack stage will be exponential. The exponential development proceeds until the point when it achieves the greatest development. Starting here, advance development will begin to decay. The decay may be caused by the diminishing nourishment sources, for example, sugar, amino acids or fat, which have been taken up by bacteria during their exponential development period. The inadequate sustenance will debilitate the practicality of microorganisms to keep developing [19].

The formulation of fermented corn milk was made into effervescent granule in different concentration of acids which formula 1 contained only citric acid $23.84 \%$, formula 2 only tartaric acid $23.84 \%$ and formula 3 containing the combination of citric acid $7.94 \%$ and tartaric acid $15.9 \%$. All formulas were done some evaluations for corn milk effervescent granules including physical and chemical properties of granules and hedonic test. Regarding this, the best formulation was formula 3 containing the combination acids because all tests showed good results and meet the requirements of each test particularly hedonic test and also formula 2 but it still needed to improve on texture and color of granules. Otherwise, formula 1 showed unsatisfactory results of some tests such as \% LOD, \% MC, dissolution time, and hedonic tests.

This means that formula 3 containing citric acid and tartaric acid combination give the best effervescent granules relating to the stoichiometric rule in the solution [20]. The ratio of citric acid, tartaric acid and sodium bicarbonate based on the stoichiometric rule, i.e. one molecule of citric acid will react with three sodium bicarbonate molecules while tartaric acid reacts with two sodium bicarbonate molecules so that the ratio of sodium bicarbonate, citric acid and tartrate is $3.4: 1: 2$. With an effervescent formulation in the powder, the degree of solubility of these materials will be slightly reduced when water is added. On the contrary, a rapid and powerful and uncontrollable vacuum reaction can be reduced. The formation reaction of froth that occurs is not to spill effervescent which can lead to the reduced weight of the contents of the solution [11].

\section{CONCLUSION}

Corn milk can be formulated into effervescent granule as probiotic drink based on all evaluation tests, particularly formula 3 containing citric acid and the tartaric acid combination is the best formulation.

\section{ACKNOWLEDGEMENT}

The authors are thankful to the Ministry of Research, Technology, and Higher Education of Indonesia, which has funded this research by grant competition (decentralization grant). Besidesthat, we also thank to LPPM of State University of Gorontalo, Indonesia giving excellent technical support.

\section{AUTHORS CONTRIBUTIONS}

All the authors have contributed equally

\section{CONFLICTS OF INTERESTS}

All authors have none to declare

\section{REFERENCES}

1. Reyes FGR, Varseveld GW, Kuhn MC. Sugar composition and flavor quality of high sugar (Shrunken) and normal sweet corn. J Food Sci 1982;48:490-2.

2. Supavititpatana P, Wirjantoro TI, Raviyan P. Characteristics and shelf-life of corn milk yogurt. CMU J Nat Sci 2010;9:133-47.

3. Yasni S, Maulydia A. Development of corn milk yoghurt using the mixed culture of Lactobacillus delbruekii, Streptococcus salivarus, and Lactobacillus casei. Hayati J Biosci 2014;21:1-7.

4. Ansel HC, Popovich NG, Allen LV. Pharmaceutical dosage forms and drug delivery systems. B. I. Waverly, New Delhi; 1999. p. 469-71.

5. Rukmana R. The corn production in Indonesia. Publisher Aneka Ilmu. Semarang; 2003.

6. Lieberman HA, Lachman L, SchwartzJ B. Pharmaceutical dosage forms: tablets, Marcel Dekker inc. Vol. 1-2, New York; 1993. p. 285.

7. Gupta R, Sharma P, Garg A, Soni A, Sahu A, Rai S, et al. Formulation and evaluation of herbal effervescent granules incorporated with Calliandra Haematocephala leaves extract. Indo Am J Pharm Res 2013;3:4366-71.

8. Nagashima AI, Pansiera PE, Baracat MM, Gómez RJH. Development of effervescent products, in powder and tablet form, supplemented with probiotics Lactobacillus acidophilus and Saccharomyces boulardii. Food Sci Technol Campinas 2013;33:605-11.

9. Muhajir R, Rahim A, Hutomo GS. The physical and chemical characteristics of sweet corn milk at a different boiling time. J Agroland 2014;21:95-103.

10. Anshory H, Syukuri Y, Malasari Y. The formulation of an effervescent tablet of ginseng jawa (Tlinumpaniculatum) extracts with aspartam variations. J Sci Pharm 2007;4:1-7.

11. Syamsul ES, Supomo. Formulation of effervescent powder of water extract of bawang tiwai (EleuterinePalmifolia) as a healthy drink. Trad Med J 2014;19:113-7.

12. Mohrle R. Effervescent tablets. In: lieberman HA, Lachman L. eds. Vol. I. Pharmaceutical Dosage Form Tablet; 1989. p. 287, 289, 295.

13. Limyati VY. The formulation of effervescent powder of carrot extract (Daucuscarota L). Thesis. Faculty of Agriculture Technology. Padang: Andalas University; 2009.

14. Lee WJ, Lucey JA. Formation and physical properties of yoghurt. Asian-Aust J Anim Sci 2010;23:1127-36.

15. Cobbeldick RH. High sugar sweet corn. Ontario: Factsheet, Ontario Department of Agriculture; 2012.

16. Aswal P, Priyadarsi S, Anubha S. Yoghurt preparation, characteristic and recent advancements. Cibtech J Bioprotocols 2012;2:2319-40.

17. Fernandez Garcia E, Vilaviciosa C, McGregor JU. Determination of organic acid during fermentation and cold storage of yoghurt. J Dairy Sci 1994;77:2934-9.

18. Tamime AY, Robinson RK. Yoghurt science and technology. New York: Pergamon Press Ltd; 1989.

19. Gilliland SE, Reilly SS, Kim GB, Kim HS. Viability during storage of selected probiotic lactobacilli and bifidobacteria in the yoghurt-like product. J Food Sci 2002;67:3091-5.

20. Velivela S, Abbulu K, Vima M, Pati NB. Formulation and in vitro evaluation of ritonavir floating tablets by melt granulation technique. Int J Appl Pharm 2016;8:12-5. 